\title{
First single crystal growth and structural analysis of superconducting layered bismuth oxyselenide; $\mathrm{La}(\mathrm{O}, \mathrm{F}) \mathrm{BiSe}_{2}$
}

\author{
Masashi TANAKA $^{\mathrm{a}^{*}}$, Masanori NAGAO ${ }^{\mathrm{b}}$, Yoshitaka MATSUSHITA ${ }^{\mathrm{a}}$, Masaya FUJIOKA ${ }^{\mathrm{a}}$, \\ Saleem J. DENHOLME ${ }^{\mathrm{a}}$, Takahide YAMAGUCHI ${ }^{\mathrm{a}}$, Hiroyuki TAKEYA ${ }^{\mathrm{a}}$, \\ and Yoshihiko TAKANO
}

${ }^{a}$ National Institute for Materials Science, 1-2-1 Sengen, Tsukuba, Ibaraki 305-0047, Japan

${ }^{\mathrm{b}}$ University of Yamanashi, 7-32 Miyamae, Kofu, Yamanashi 400-8511, Japan

*Corresponding author:

Masashi Tanaka

E-mail: Tanaka.Masashi@nims.go.jp

Postal address: National Institute for Materials Science

1-2-1 Sengen, Tsukuba, Ibaraki 305-0047, Japan

Tel.: (+81)29-851-3354 ext. 2976 


\section{Abstract}

Single crystals of $\mathrm{La}(\mathrm{O}, \mathrm{F}) \mathrm{BiSe}_{2}$ were successfully grown for the first time by a $\mathrm{CsCl}$ flux method.

Single crystal X-ray structural analysis clearly showed that $\mathrm{La}(\mathrm{O}, \mathrm{F}) \mathrm{BiSe}_{2}$ crystalizes with space group P4/nmm (lattice parameters $a=4.1408(2) \AA, c=14.1096(6) \AA$ ). The structure is composed of alternating $\mathrm{BiSe}_{2}$ and $\mathrm{La}(\mathrm{O}, \mathrm{F})$ layers. The bond distances and angles are similar to those of $\mathrm{La}(\mathrm{O}, \mathrm{F}) \mathrm{BiS}_{2}$. The bond valence sum calculation indicates the refined structure is slightly cation rich, suggesting the charge neutrality should be kept by modification of valence state of the cations. Magnetic susceptibility and resistivity measurements showed the compound is a superconductor with a transition temperature of $3.6 \mathrm{~K}$, which is higher than that of as-grown $\mathrm{La}(\mathrm{O}, \mathrm{F}) \mathrm{BiS}_{2}$.

\section{Keywords:}

Single crystals growth; Single crystal X-ray structural analysis; $\mathrm{BiSe}_{2}$-based superconductor 


\section{Introduction}

After the discovery of superconductivity in $\mathrm{Bi}_{4} \mathrm{O}_{4} \mathrm{~S}_{3}[1]$, much attention has been paid to synthesizing $\mathrm{BiS}_{2}$-based compounds. The $\mathrm{BiS}_{2}$-based compounds have a layered structure composed of superconducting $\mathrm{BiS}_{2}$ layers and charge reservoir blocking layers similar to that of cuprate or Fe-based superconductors. For the $\mathrm{Bi}_{4} \mathrm{O}_{4} \mathrm{~S}_{3}$ case, it is composed of a superconducting layer $\mathrm{Bi}_{2} \mathrm{~S}_{4}$ and a blocking layer $\mathrm{Bi}_{4} \mathrm{O}_{4}\left(\mathrm{SO}_{4}\right)_{1-x}$. There are other $\mathrm{BiS}_{2}$-based superconductors with another type of the blocking layer $\mathrm{La}(\mathrm{O}, \mathrm{F})$ (similar to the Fe-based superconductor $\mathrm{La}(\mathrm{O}, \mathrm{F}) \mathrm{FeAs}[2])$. $\mathrm{La}(\mathrm{O}, \mathrm{F}) \mathrm{BiS}_{2}$ synthesized under ambient pressure shows superconductivity with a transition temperature $\left(T_{\mathrm{c}}\right)$ of $\sim 2.5 \mathrm{~K}$ [3]. The $T_{\mathrm{c}}$ is enhanced as high as $11.5 \mathrm{~K}$ under high pressure [4], and this is the current record for a $\mathrm{BiS}_{2}$-based superconductors. $\mathrm{BiS}_{2}$-based superconductors with various types of blocking layers have been developed so far, such as $\operatorname{Ln}(\mathrm{O}, \mathrm{F}) \mathrm{BiS}_{2}(\operatorname{Ln}=\mathrm{La}, \mathrm{Ce}, \mathrm{Pr}, \mathrm{Nd}, \mathrm{Yb})$ [3, 5-9], $(\mathrm{La}, M) \mathrm{OBiS}_{2}(M=\mathrm{Th}, \mathrm{Hf}, \mathrm{Zr}, \mathrm{Ti})[10],(\mathrm{Sr}, \mathrm{La}) \mathrm{FBiS}_{2}[11] . \operatorname{Ln}(\mathrm{O}, \mathrm{F}) \mathrm{BiS}_{2}(\operatorname{Ln}=\mathrm{La}, \mathrm{Ce}, \mathrm{Nd})$ have been prepared as single crystals using alkali metal chloride flux methods [12-14]. The single crystal X-ray structural analysis for $\mathrm{La}(\mathrm{O}, \mathrm{F}) \mathrm{BiS}_{2}$ and $\mathrm{Nd}(\mathrm{O}, \mathrm{F}) \mathrm{BiS}_{2}$ determined the bonding distances and angles precisely $[15,12]$. Especially in the case of $\mathrm{La}(\mathrm{O}, \mathrm{F}) \mathrm{BiS}_{2}$, the structural investigation of different $\mathrm{F}$ contents were performed by Miura et al. [15]. They showed that the substitution of $\mathrm{O}$ by $\mathrm{F}$ results in the distortion of the Bi-S plane.

On the other hand, modification of superconducting layers is a very challenging issue. Only two cases have been reported in polycrystalline samples: $\mathrm{LaO}_{0.5} \mathrm{~F}_{0.5} \mathrm{BiSSe}\left(T_{\mathrm{c}} \sim 3.8 \mathrm{~K}\right)[16]$ and 
$\mathrm{La}(\mathrm{O}, \mathrm{F}) \mathrm{BiSe}_{2}\left(T_{\mathrm{c}} \sim 2.6 \mathrm{~K}\right)$ [17]. It is necessary to obtain single crystals of the $\mathrm{BiSe}_{2}$-based material in order to clarify the superconducting mechanism and precise crystal structure so as to be able to design a new compound with a higher $T_{\mathrm{c}}$.

In this study, we have succeeded in preparing single crystals of $\mathrm{La}(\mathrm{O}, \mathrm{F}) \mathrm{BiSe}_{2}$ by a $\mathrm{CsCl}$ flux method and carried out various characteristic measurements including single crystal X-ray diffraction. Here, we discuss the bonding nature and superconductivity of this compound. 


\section{Experimental}

\subsection{Preparation of single crystals}

Single crystals of $\mathrm{La}(\mathrm{O}, \mathrm{F}) \mathrm{BiSe}_{2}$ were prepared by an alkali metal chloride flux method. Since $\mathrm{CsCl}$ exhibits less reactivity with the quartz tube at high temperature (unlike other alkali metal chlorides), $\mathrm{CsCl}$ was selected as the flux material. The powders of $\mathrm{La}$ (Kojundo, 99.9\%), $\mathrm{Bi}_{2} \mathrm{O}_{3}$ (Wako, 99.9\%), $\mathrm{BiF}_{3}$ (Kojundo, 99.9\%), Bi (Kojundo, 99.99\%), $\mathrm{Bi}_{2} \mathrm{Se}_{3}$ (Kojundo, 99.9\%), Se (Kojundo, 99.9\%) were mixed with the ratio of $\mathrm{La}: \mathrm{Bi}_{2} \mathrm{O}_{3}: \mathrm{BiF}_{3}: \mathrm{Bi}: \mathrm{Bi}_{2} \mathrm{Se}_{3}: \mathrm{Se}=6: 1: 1: 1: 1: 9$, which corresponds to nominal composition of $\mathrm{LaO}_{0.5} \mathrm{~F}_{0.5} \mathrm{BiSe}_{2}$. Selenium vaporizes and increases its vapor pressure above $\sim 690{ }^{\circ} \mathrm{C}$. In order to reduce the risk of explosion of the quartz tube, the $\mathrm{Bi}_{2} \mathrm{Se}_{3}$ powder was used as a starting material for Se as well as the Bi sources. The starting powders of $0.8 \mathrm{~g}$ were mixed with $5 \mathrm{~g}$ of $\mathrm{CsCl}$ (Kojundo, 99.9\%). The mixture was sealed in an evacuated quarts tube, and then heated to $880^{\circ} \mathrm{C}$ in $10 \mathrm{~h}$, then gradually heated up to $900{ }^{\circ} \mathrm{C}$ in $2 \mathrm{~h}$. The temperature was kept for $10 \mathrm{~h}$, followed by cooling to $650{ }^{\circ} \mathrm{C}$ at a rate of $1{ }^{\circ} \mathrm{C} / \mathrm{h}$, then the sample was cooled down to room temperature in the furnace. The obtained materials were washed and rinsed by water, ethanol, and acetone in order to remove the flux material $\mathrm{CsCl}$.

\subsection{Characterization}

Single crystal X-ray structural analysis was carried out using a Rigaku AFC11 Saturn CCD diffractometer with a VariMax confocal X-ray optical system for Mo K $\alpha$ radiation $(\lambda=0.71073 \AA$ ). 
Prior to the diffraction experiment, the crystals were cooled to $160 \mathrm{~K}$ in a cold $\mathrm{N}_{2}$ gas flow, in order to suppress the thermal displacement factor. Cell refinement and data reduction were carried out by the program $d^{*}$ trek package in CrystalClear software suite [18]. The structure was solved by the direct method using SHELXS [19], and was refined with the program SHELXL [19] in the WinGX software package [20]. Back scattered electron (BSE) images and energy-dispersive X-ray (EDX) spectra were observed using a scanning electron microscope (Hitachi SU-70, EDAX Genesis XM2).

Temperature dependence of magnetic susceptibility was measured using a SQUID magnetometer (MPMS, Quantum Design) down to $1.8 \mathrm{~K}$ under a field of $10 \mathrm{Oe}$, and the field was applied parallel to the $c$-axis. Temperature dependence of electrical resistivity was measured down to 2.0 K, using a standard four-probe method with constant current mode by a Physical Property Measurement System (PPMS, Quantum Design). The electrodes were attached in the $a b$-plane with silver paste. 


\section{Results and Discussion}

\subsection{Crystal structure of $\mathrm{La}(\mathrm{O}, \mathrm{F}) \mathrm{BiSe}_{2}$}

BSE image of a typical single crystal is shown in Fig.1(a). The image suggests the crystal has a uniform composition, and no local precipitation of metal. The composition was analyzed by EDX point analysis at several sections of the crystal. Fig.1(b) shows a typical EDX spectrum at a point marked by the red cross in Fig.1(a). The averaged compositional ratio of elements is estimated to be $\mathrm{La}: \mathrm{Bi}: \mathrm{Se}: \mathrm{O}: \mathrm{F}=0.98: 0.92: 2: 0.50: 0.19$, in which the ratio was normalized to $\mathrm{Se}=2$. The atomic ratio except for $\mathrm{O}$ and $\mathrm{F}$ elements is in good agreement with the nominal composition, suggesting that the single crystal has a composition $\mathrm{La}\left(\mathrm{O}_{1-x} \mathrm{~F}_{x}\right) \mathrm{BiSe}_{2}$. It should be noted that the analysis always detected a slight excess of $\mathrm{La}$ in relation to $\mathrm{Bi}$.

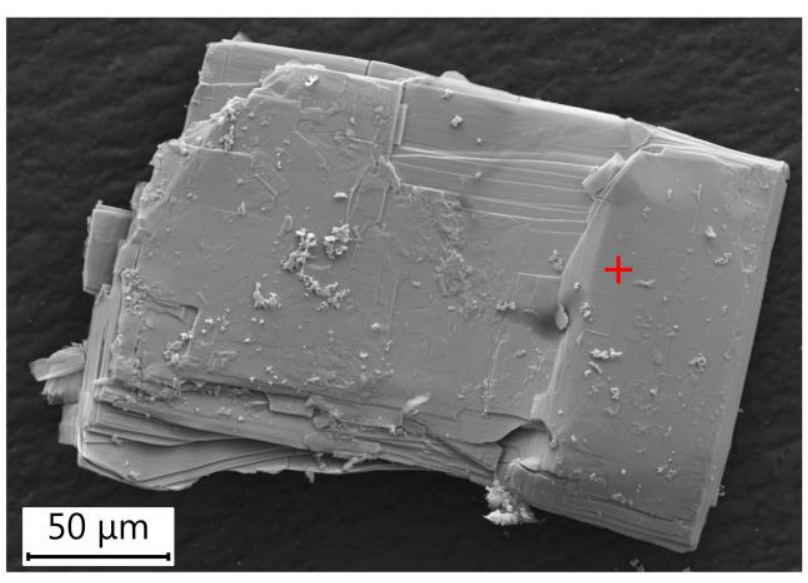

(a)

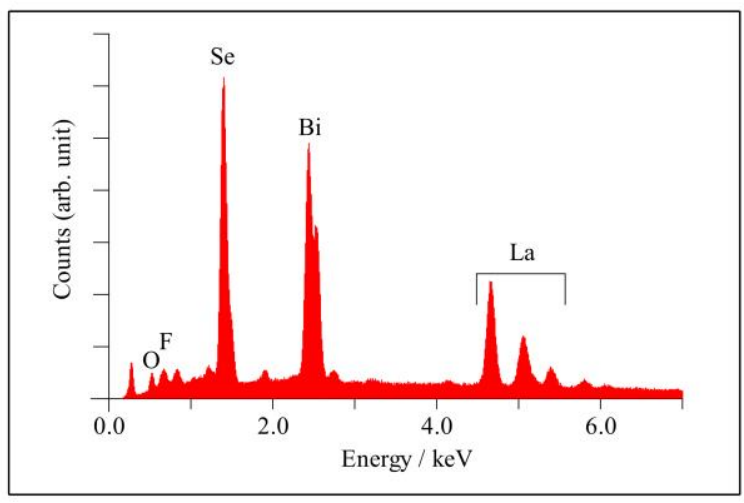

(b)

Figure 1. BSE image (a) and EDX result (b) of an obtained single crystal. 
The X-ray single crystal analysis was successfully performed. Details of the single-crystal structure analysis at $160 \mathrm{~K}$ and crystallographic parameters are listed in Table 1 and Table 2. The compound crystallizes with space group P4/nmm (lattice parameters $a=4.1408(2) \AA, c=14.1096(6)$ $\AA$, and $Z=1$ ). All atoms were located at special positions and their anisotropic displacement factors were all positive with similar values, appearing physically reasonable. The ratio of $\mathrm{O}$ and $\mathrm{F}$ was estimated to be $\mathrm{O}: \mathrm{F}=0.82: 0.18$, namely $\mathrm{La}\left(\mathrm{O}_{0.82} \mathrm{~F}_{0.18}\right) \mathrm{BiSe}_{2}$, from the occupancy refinement under constrain of Occ. $(\mathrm{O})+$ Occ. $(\mathrm{F})=1$. A F content of 0.18 is in good agreement with the $\mathrm{F}$ ratio to Se in the EDX result, 0.19 .

A schematic illustration of the crystal structure is shown in Fig. 2(a). The crystal has an alternate stacking of $\mathrm{BiSe}_{2}$ pyramids and $\mathrm{La}_{2}(\mathrm{O} / \mathrm{F})_{2}$ layers; the basic structure of this crystal is isostructural with $\mathrm{La}(\mathrm{O}, \mathrm{F}) \mathrm{BiS}_{2}$ [3]. The ORTEP representation is shown in Fig. 2(b). It is necessary to mention about residual peaks/holes around $\mathrm{Bi}$ and La sites. There are relatively large residual maximum densities $\left(<\sim 5 \mathrm{e}^{-} / \AA^{3}\right)$ around $\mathrm{Bi}$ and La sites even though the $R 1$ value falls as small as $\sim 3 \%$. Fig. 3 shows the precession photographs reconstructed from the observed single crystal diffraction data. It is clearly shown that no modulated structure was observed. This finding suggests that the large residual densities are attributed to local disorder of $\mathrm{Bi} / \mathrm{La}$-sites in its crystal structure similar to X-ray absorption spectroscopy results in $\mathrm{BiS}_{2}$-based materials [21]. Since the EDX result always shows a La-rich content compared with that of the $\mathrm{Bi}$, one possibility is that a little amount of La migrates to the Bi site as shown in Fig. 2(b) (Bi' and La' sites). In this model, the total occupancy 
Table 1. Crystallographic data for the $\mathrm{La}(\mathrm{O}, \mathrm{F}) \mathrm{BiSe}_{2}$

\begin{tabular}{ll}
\hline Structural formula & $\mathrm{La}_{2.02}\left(\mathrm{O}_{0.82} \mathrm{~F}_{0.18}\right)_{2} \mathrm{Bi}_{1.98} \mathrm{Se}_{4}$ \\
Formula weight & 1043.29 \\
Crystal dimensions $(\mathrm{mm})$ & $0.100 \times 0.090 \times 0.030$ \\
Crystal shape & Platelet \\
Crystal system & Tetragonal \\
Space group & $P 4 / n m m(\mathrm{No.192})$ \\
$a(\AA)$ & $4.1408(2)$ \\
$c(\AA)$ & $14.1096(6)$ \\
$V\left(\AA^{3}\right)$ & $241.93(3)$ \\
$Z$ & 1 \\
$d_{\text {calc }}\left(\mathrm{g} / \mathrm{cm}{ }^{3}\right)$ & 7.174 \\
Temperature $(\mathrm{K})$ & 160 \\
$\lambda(\AA)$ & $0.71073(\mathrm{MoK} \alpha)$ \\
$\mu\left(\mathrm{mm}{ }^{-1}\right)$ & 59.900 \\
Absorption correction & multi-scan \\
$\theta_{\text {max }}\left({ }^{\circ}\right)$ & 46.242 \\
Index ranges & $-7<h<8,-8<k<8,-28<l<28$ \\
Total reflections & 9173 \\
Unique reflections & 700 \\
Observed $[I \geq 2 \sigma(I)]$ & 694 \\
$R_{\text {int }}$ for all reflections & 0.0244 \\
No. of variables & 23 \\
$R 1 / w R 2[I \geq 2 \sigma(I)]$ & $0.0243 / 0.0634$ \\
$R 1 / w R 2$ (all data) & $0.0244 / 0.0636$ \\
Max./Min. residual density $\left(\mathrm{e}^{-} / \AA^{3}\right)$ & $4.923 /-2.039$ \\
\hline & \\
&
\end{tabular}


Table 2. Atomic coordinates, atomic displacement parameters $\left(\AA^{2}\right)$, and bond valence sum (BVS) for the $\mathrm{La}\left(\mathrm{O}_{0.82} \mathrm{~F}_{0.18}\right) \mathrm{BiSe}_{2}$

\begin{tabular}{|c|c|c|c|c|c|c|c|c|c|c|}
\hline Site & Wyck. & S.O.F & $x / a$ & $y / b$ & $z / c$ & $U_{11}$ & $U_{22}$ & $U_{33}$ & $U_{\text {eq }}$ & BVS \\
\hline $\mathrm{La}$ & $2 c$ & 1 & $1 / 4$ & $1 / 4$ & $0.09052(3)$ & $0.01474(10)$ & $0.01474(10)$ & $0.01281(14)$ & $0.01410(9)$ & +2.94 \\
\hline $\mathrm{Bi}$ & $2 c$ & 0.98 & $1 / 4$ & $1 / 4$ & $0.62301(2)$ & $0.01420(8)$ & $0.01420(8)$ & $0.01177(16)$ & $0.01339(8)$ & +3.10 \\
\hline $\mathrm{Bi}$ & $2 c$ & 0.01 & $1 / 4$ & $1 / 4$ & $0.5855(18)$ & & & & $0.003(5)$ & +0.02 \\
\hline La' & $2 c$ & 0.01 & $1 / 4$ & $1 / 4$ & $0.664(2)$ & & & & $0.004(6)$ & +0.08 \\
\hline $\mathrm{Se} 1$ & $2 c$ & 1 & $1 / 4$ & $1 / 4$ & $0.81260(5)$ & $0.01343(15)$ & $0.01343(15)$ & $0.0102(2)$ & $0.01235(11)$ & -2.17 \\
\hline $\mathrm{Se} 2$ & $2 c$ & 1 & $1 / 4$ & $1 / 4$ & $0.38739(6)$ & $0.01299(16)$ & $0.01299(16)$ & $0.0190(3)$ & $0.01499(13)$ & -2.06 \\
\hline $\mathrm{O}$ & $2 a$ & 0.82 & $3 / 4$ & $1 / 4$ & 0 & $0.0131(11)$ & $0.0131(11)$ & $0.0120(14)$ & $0.0128(8)$ & -1.62 \\
\hline $\mathrm{F}$ & $2 a$ & 0.18 & $3 / 4$ & $1 / 4$ & 0 & $0.0131(11)$ & $0.0131(11)$ & $0.0120(14)$ & $0.0128(8)$ & -0.26 \\
\hline
\end{tabular}

Note: $U_{12}, U_{13}$, and $U_{23}$ are 0 , and $U_{\text {eq }}$ is defined as one third of the trace of the orthogonalized $U$ tensor. 

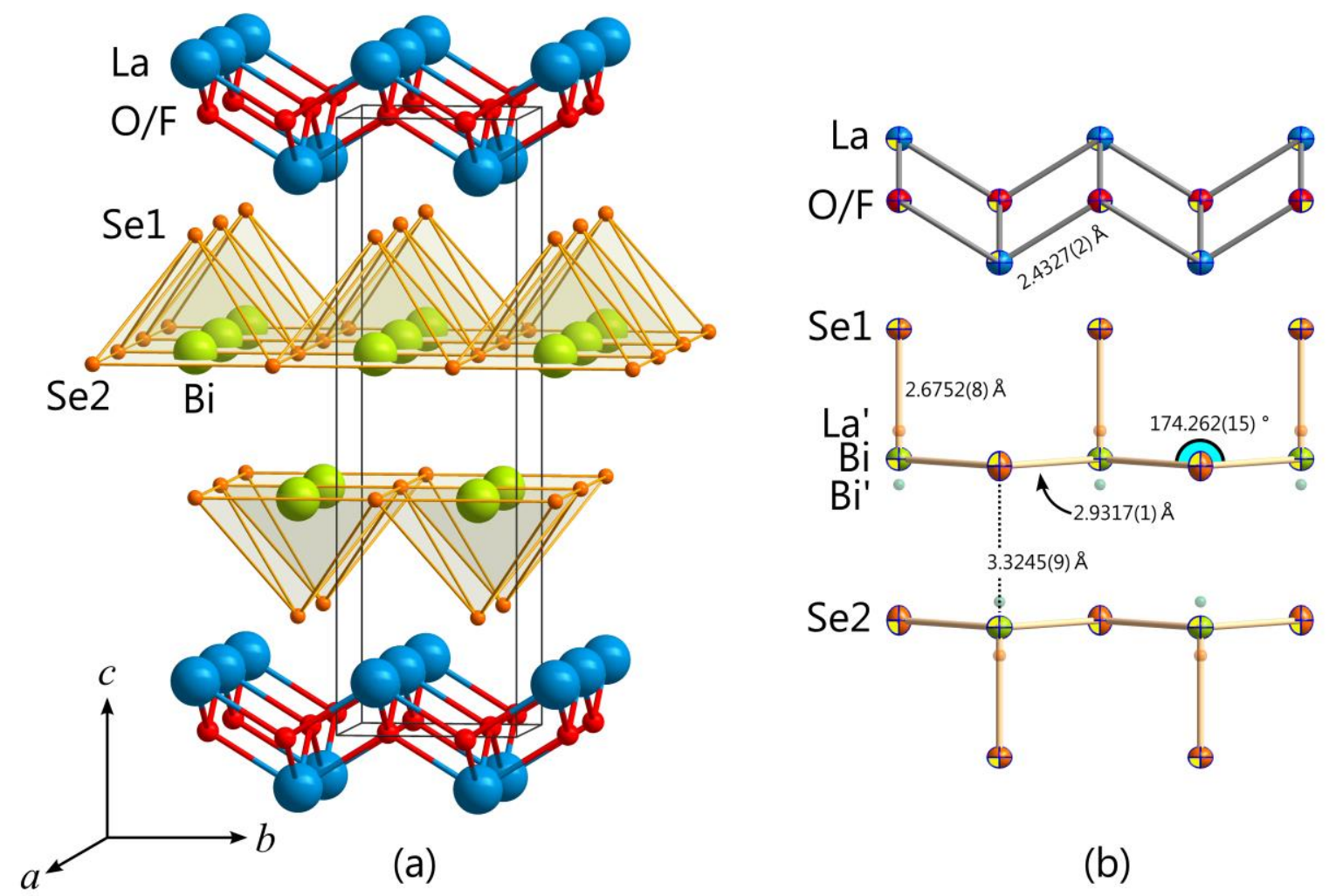

(b)

Figure 2. Crystal structure of $\mathrm{La}(\mathrm{O}, \mathrm{F}) \mathrm{BiSe}_{2}$ (a) and its local ORTEP representation with the selected bonding distances and angles (b). Displacement ellipsoids are drawn at an $80 \%$ probability level. 

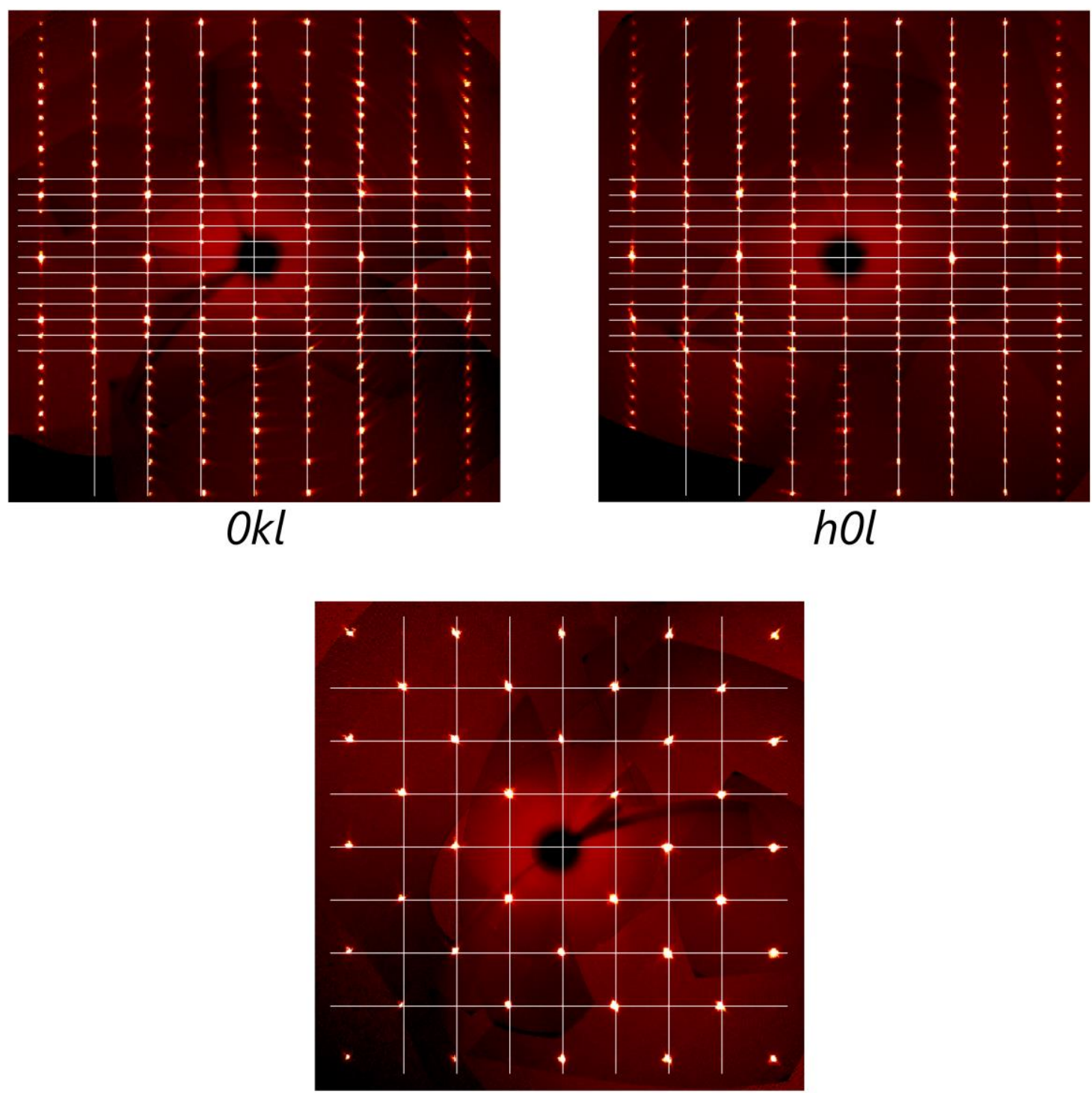

$h k 0$

Figure 3. Precession images synthesized from the CCD single crystal diffraction data for $\mathrm{La}(\mathrm{O}, \mathrm{F}) \mathrm{BiSe}_{2}$. All lines are a guide for the eye. 
and valence of $\mathrm{Bi}$ and $\mathrm{La}$ were constrained to keep 1.0 and +3 , respectively. The final refined composition was $\mathrm{La}_{1.010}\left(\mathrm{O}_{0.82} \mathrm{~F}_{0.18}\right) \mathrm{Bi}_{0.992} \mathrm{Se}_{2}$. This refinement converged to $R 1=2.44 \%$, which has a considerably lower value than that of the model excluding the displacement $(R 1=2.82 \%)$. However, we cannot exclude the possibility of self-disorder of the $\mathrm{Bi}$ atoms. There are no considerable differences in $R 1$ values between the case of $\mathrm{Bi} / \mathrm{Bi}$ and $\mathrm{Bi} / \mathrm{La}$ disorder, although the lowest $R 1$ value was obtained in the model described above.

Some selected bond distances and angles are given in Fig. 2(b) and Table 3. Bi atoms are six coordinated and bonded with Se atoms in three kinds such as Bi-Se1, intra-plane Bi-Se2, and inter-plane Bi-Se2 bondings. The interatomic distance of intra-plane Bi-Se2 is 2.9317(1) $\AA$. On the other hand, the inter-plane $\mathrm{Bi}-\mathrm{Se} 2$ is much longer $(3.3242(9) \AA)$ and the Bi-Se1 is shorter $(2.6752(8) \AA$ ) than that of the intra-plane Bi-Se2. This tendency of bond lengths is similar to that of $\mathrm{La}(\mathrm{O}, \mathrm{F}) \mathrm{BiS}_{2}$ [3]. The intra-plane Se-Bi-Se angle in the present crystal is $174.262(15)^{\circ}$. In $\mathrm{La}(\mathrm{O}, \mathrm{F}) \mathrm{BiS}_{2}$, it has been reported that the amount of $\mathrm{F}$ affects not only the carrier concentration but also creates a distortion of the Bi-S plane [14]. The Bi-Se plane is more distorted than the Bi-S plane in $\mathrm{La}\left(\mathrm{O}_{1-x} \mathrm{~F}_{x}\right) \mathrm{BiS}_{2}$ with $x \sim 0.23$. Bond valence sum (BVS) was estimated from the observed bond distances and the $r_{0}$ and $B$ values of nominal valence $\mathrm{La}^{3+}, \mathrm{Bi}^{3+}, \mathrm{Se}^{2-}, \mathrm{O}^{2-}$, $\mathrm{F}^{-}$provided by Brown [22]. The BVS values are also listed in Table.2. According to the refined composition $\mathrm{La}_{1.010}\left(\mathrm{O}_{0.82} \mathrm{~F}_{0.18}\right) \mathrm{Bi}_{0.992} \mathrm{Se}_{2}$, the nominal valence summation should be +0.19 , based on nominal valences. On the other hand, the BVS of $\mathrm{Bi}$ and La was estimated to be +6.11 , indicating +0.11 different from charge neutrality. Both results indicate the refined structure is slightly cation rich, suggesting the charge neutrality should be kept by modification of valence state of Bi like as the result of X-ray photoemission spectroscopy for $\mathrm{BiS}_{2}$-based compound [23]. 
Table 3. Selected bond lengths $(\AA)$ and angles $\left(^{\circ}\right)$ of the $\mathrm{La}\left(\mathrm{O}_{0.82} \mathrm{~F}_{0.18}\right) \mathrm{BiSe}_{2}$ single crystal

\begin{tabular}{rrll}
\hline \multicolumn{1}{l}{ Distance } & & & \\
La-O/F $\times 4$ & $2.4327(2)$ & $\mathrm{Bi}-\mathrm{Se} 1$ & $2.6752(8)$ \\
$\mathrm{La}-\mathrm{Se} 1 \times 4$ & $3.2314(4)$ & $\mathrm{Bi}-\mathrm{Se} 2$ [inter plane] & $3.3245(9)$ \\
& & $\mathrm{Bi}-\mathrm{Se} 2$ [in plane] $\times 4$ & $2.9317(1)$ \\
Angle & & & \\
La-O/F-La & $105.998(8)$ & $\mathrm{Se} 1-\mathrm{Bi}-\mathrm{Se} 2$ & $92.869(14)$ \\
La-Se1-La & $79.690(11)$ & $\mathrm{Se} 2-\mathrm{Bi}-\mathrm{Se} 2$ [inter-plane] & $87.131(13)$ \\
& & $\mathrm{Se} 2-\mathrm{Bi}-\mathrm{Se} 2$ [intra-plane] & $174.262(15)$ \\
\hline
\end{tabular}

\subsection{Superconductivity}

Fig. 4 shows the temperature dependence of the magnetic susceptibility for a single crystal of $\mathrm{La}(\mathrm{O}, \mathrm{F}) \mathrm{BiSe}_{2}$.

The diamagnetic signal corresponding to superconductivity appears below $3.6 \mathrm{~K}$. The shielding and Meissner volume fraction at $1.8 \mathrm{~K}$ was estimated to be $\sim 31.8 \%$ and $\sim 14.6 \%$, respectively. The inset shows the temperature dependence of the resistivity along the $a b$-plane in the single crystal. It showed a sharp resistivity drop at $3.6 \mathrm{~K}$, and zero resistivity was observed at $3.2 \mathrm{~K}$, in accordance with the superconducting transition temperature $T_{\mathrm{c}}$ found in the magnetic susceptibility measurement.

Note that the $T_{\mathrm{c}}$ is $1 \mathrm{~K}$ higher than that of previously reported polycrystalline result [17]. Currently, the reason of the $T_{\mathrm{c}}$ difference is unclear but assuming that it is attributed to the $\mathrm{F}$ content and higher crystallinity. X-ray single crystal analysis showed the corrugation in the Bi-Se layer is slightly larger than the Bi-S layer of the $\mathrm{BiS}_{2}$-based superconductor. A flat Bi-S plane would result in better hybridization of the $p_{x} / p_{y}$ orbitals of $\mathrm{Bi}$ and $\mathrm{S}$ [15]. If the $\mathrm{Bi}-\mathrm{Se}$ plane could be flattened by applying chemical or physical 
pressure, such as optimization of the F-content or uniaxial compression, an overlapping of the Bi- and Se- $p$ orbitals would be enhanced and may realize higher $T_{\mathrm{c}}$ in this system.

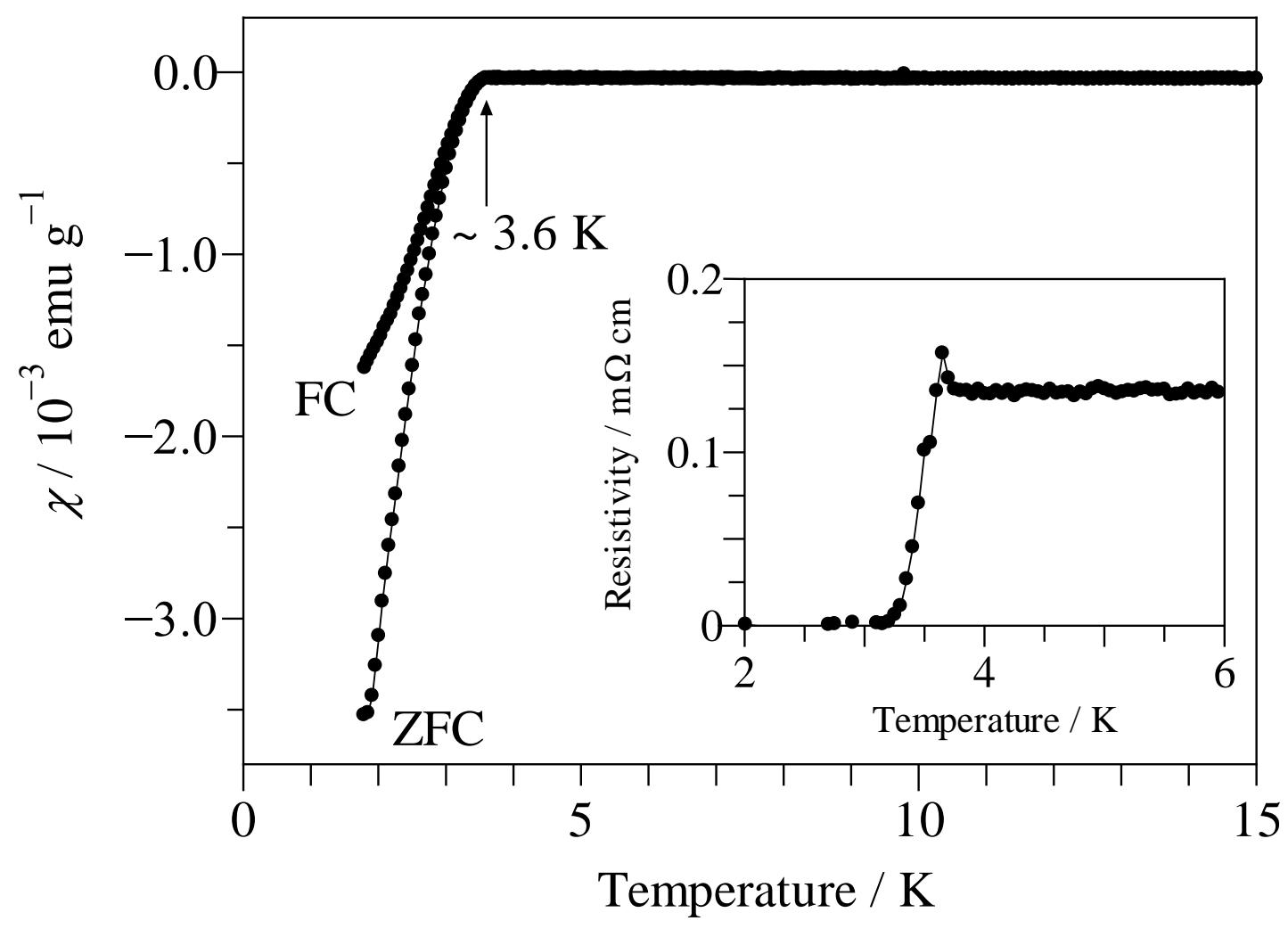

Figure 4. Temperature dependence of magnetic susceptibility of the single crystal of $\mathrm{La}(\mathrm{O}, \mathrm{F}) \mathrm{BiSe}_{2}$ in zero-field cooling (ZFC) and field cooling (FC) mode. The inset shows temperature dependence of resistivity with an enlargement of the superconducting transition. 


\section{Conclusion}

Single crystals of $\mathrm{La}(\mathrm{O}, \mathrm{F}) \mathrm{BiSe}_{2}$ were successfully grown by the $\mathrm{CsCl}$ flux method. The $\mathrm{X}$-ray structural analysis revealed $\mathrm{La}(\mathrm{O}, \mathrm{F}) \mathrm{BiSe}_{2}$ crystalized with space group P4/nmm (lattice parameters $a=4.1408(2) \AA, c$

= 14.1096(6) $\AA$ ). The magnetic susceptibility and resistivity measurements show a clear superconducting transition at $3.6 \mathrm{~K}$. The structural analysis suggests the possibility of raising the $T_{\mathrm{c}}$ if the corrugated $\mathrm{Bi}-\mathrm{Se}$ layer can be flattened by applying chemical or physical pressure as well as $\mathrm{BiS}_{2}$-based superconductors.

\section{Acknowledgment}

This work was partially supported by Japan Science and Technology Agency through Strategic International Collaborative Research Program (SICORP-EU-Japan) and Advanced Low Carbon Technology R\&D Program (ALCA) of the Japan Science and Technology Agency.

\section{References}

[1] Y. Mizuguchi, H. Fujihisa, Y. Gotoh, K. Suzuki, H. Usui, K. Kuroki, S. Demura, Y. Takano, H. Izawa, O. Miura: Phys. Rev. B 86 (2012) 220510.

[2] Y. Kamihara, T. Watanabe, M. Hirano, H. Hosono: J. Am. Chem. Soc. 130 (2008) 3296.

[3] Y. Mizuguchi, S. Demura, K. Deguchi, Y. Takano, H. Fujihisa, Y. Gotoh, H. Izawa and O. Miura: J. Phys. Soc. Jpn. 81 (2012) 114725.

[4] Y. Mizuguchi, T. Hiroi, J. Kajitani, H. Takattsu, H. Kadowaki, O. Mirura: J. Phys. Soc. Jpn. 83 (2014) 
053704.

[5] K. Deguchi, Y. Takano, Y. Mizuguchi: Sci. Technol. Adv. Mater. 13 (2012) 054303.

[6] J. Xing, S. Li, X. Ding, H. Yang and H.-H. Wen: Phys. Rev. B 86 (2012) 214518.

[7] R. Jha, A. Kumar, S. K. Singh, V. P. S. Awana: J. Supercond. Nov. Magn. 26 (2013) 499.

[8] S. Demura, Y. Mizuguchi, K. Deguchi, H. Okazaki, H. Hara, T. Watanabe, S. J. Denholme, M. Fujioka, T.

Ozaki, H. Fujihisa, Y. Gotoh, O. Miura, T. Yamaguchi, H. Takeya and Y. Takano: J. Phys. Soc. Jpn. 82 (2012) 033708.

[9] D. Yazici, K. Huang, B.D. White, A.H. Chang, A.J. Friedman and M.B. Maple: Philosophical Magazine 93 (2013) 673.

[10] D. Yazici, K. Huang, B. White, I. Jeon, V. Burnett, A. Friedman, I. Lum, I. Nallaiyan, S. Spagna, M. Maple: Phys. Rev. B. 87, (2013) 174512.

[11] X. Lin, X. Ni, B. Chen, X. Xu, X. Yang, J. Dai, Y. Li, X. Yang, Y. Luo, Q. Tao, G. Cao and Z. Xu: Physical Review B 87 (2013) 020504.

[12] M. Nagao, S. Demura, K. Deguchi, A. Miura, S. Watauchi, T. Takei, Y. Takano, N. Kumada, I. Tanaka: J. Phys. Soc. Jpn. 82 (2013) 113701.

[13] J. Liu, D. Fang, Z. Wang, J. Xing, Z. Du, X. Zhu, H. Yang, H.-H. Wen: arXiv:1310.0377.

[14] M. Nagao, A. Miura, S. Demura, K. Deguchi, S. Watauchi, T. Takei, Y. Takano, N. Kumada, I. Tanaka: Solid State Commun. 178 (2014) 33-36.

[15] A. Miura, M. Nagao, T. Takei, S. Watauchi, I. Tanaka, N. Kumada: J. Solid State Chem. 212 (2014) 213. 
[16] X-C. Wang, D-Y. Chen, Q. Guo, J. Yu, B-B. Ruan, Q-G. Mu, G-Fu. Chen, Z-A. Ren: arXiv:1404.7562

[17] A. Krzton-Maziopa, Z. Guguchia, E. Pomjakushina, V. Pomjakushin, R. Khasanov, H. Luetkens, P.K.

Biswas, A. Amato, H. Keller, K. Conder: J. Phys.:Condens. Matter 26 (2014) 215702.

[18] CrystalClear, Rigaku Corporation, Tokyo, Japan (2005).

[19] G. M. Sheldrick: Acta Cryst. A 64 (2008) 112.

[20] L. J. Farrugia, WinGX, J. Appl. Cryst. 45 (2012) 849.

[21] T. Sugimoto, B. Joseph, E. Paris, A. Iadecola, T. Mizokawa, S. Demura, Y. Mizuguchi, Y. Takano, N.L. Saini: Phys. Rev. B 89 (2014) 201117(R).

[22] I. D. Brown (2013) http://www.iucr.org/resources/data/data-sets/bond-valence-parameters

[23] S. Nagira, J. Sonoyama, T. Wakita, M. Sunagawa, Y. Izumi, T. Muro, H. Kumigashira, M. Oshima, K. Deguchi, H. Okazaki, Y. Takano, O. Miura, Y. Mizuguchi, K. Suzuki, H. Usui, K. Kuroki, K. Okada, Y. Muraoka, T. Yokoya: J. Phys. Soc. Jpn. 83 (2014) 033703. 